\title{
Mortalidad por influenza y neumonía en la Macrorregión del Centro de México: un análisis de sus tendencias y su distribución geográfico-climática
}

\section{Mortality Patterns of Infuenza and Pneumonia in the Macroregion of Central Mexico: An Analysis of Its Trends and Its Geographic and Climatic Distribution}

\author{
David Maximiliano ZermeÑo DíaZ \\ Facultad de Filosofía y Letras, Universidad Nacional Autónoma de México \\ México \\ Leticia GómEz MENDOZA \\ Facultad de Filosofía y Letras, Universidad Nacional Autónoma de México \\ México \\ Rodolfo AcuÑa Soto \\ Facultad de Medicina, Universidad Nacional Autónoma de México \\ México
}

\section{Resumen}

Este estudio investiga dos aspectos de la mortalidad por influenza y neumonía en la Macrorregión del Centro de México: (i) sus tendencias recientes (1979-2015) y (ii) su distribución geográfico-climática. Para ello, se ocuparon los reportes mensuales de defunciones del Sistema Nacional de Información en Salud (SINAIS) a nivel municipal, los datos poblacionales de cuatro censos nacionales y los datos de temperatura $(T)$ y humedad (ed) media mensual de la base de datos CRU-TS4.01 de la Universidad de East Anglia, Reino Unido. Los resultados respecto a (i) muestran que, pese al incremento poblacional durante el período de estudio (del 80\%), las tasas de mortalidad registraron una tendencia negativa significativa (del 60\%). Respecto a (ii), los resultados indican que la mayor mortalidad ocurre principalmente sobre tres regiones frías y secas $\left(T<16^{\circ} \mathrm{C}\right.$ y $\left.e d<10 \mathrm{hPa}\right)$ sobre el Altiplano Central, sobre las regiones montañosas de la Sierra Madre Occidental y la Sierra Madre Oriental. Esta relación mortalidad-clima, explica patrones medios, pero no anómalos, por lo que las tendencias registradas de mortalidad no pueden ser directamente relacionadas a tendencias en el clima. Similarmente, esta relación tampoco explica la mortalidad sobre las megaciu- 
dades de Ciudad de México, Guadalajara y Puebla; la mortalidad sobre estas ciudades está muy por debajo de la media de la macrorregión. Ambas excepciones sugieren que, una explicación más completa de las causas de los patrones de mortalidad en la macrorregión estudiada, necesariamente tendría que considerar factores no climáticos, como los biológicos, socio-económicos o culturales.

Palabras clave: influenza, neumonía, patrones climáticos, enfermedades respiratorias

\begin{abstract}
This work focuses the macro-region of Central Mexico to investigate two aspects of the mortality by influenza and pneumonia in Central Mexico: $(i)$ its recent trends (19792015), and (ii) its geographic and climatic distribution. The study analyzed monthly municipal reports of mortality from the National Archive of Health Information (SINAIS), population data from four National Census, monthly temperature $(T)$, and humidity (ed) data, from the Climate Research Unit of the University of East Anglia (CRU-TS4.01). With respect to $(i)$, results show that, despite a large population increase (of $80 \%$ ), mortality rate decreased significantly $(60 \%)$. With respect to (ii), results indicate that the largest mortality by influenza and pneumonia occurs mainly in two cold and dry regions $\left(T<16^{\circ} \mathrm{C}\right.$ and Tmin and $\left.e d<10 \mathrm{hPa}\right)$ : over the Central Mexican Plateau and the region formed by the leeward sides of the Sierra Madre Occidental and the Sierra Madre Oriental. This climate-mortality relation explains average geographic distributions, but not anomalous patterns; mortality trends, therefore, cannot be explain in terms of climate trends. Likewise, such relation cannot explain mortality over the largely populated megacities of Mexico City, Guadalajara y Puebla; the mortality over these cities is significantly lower than that of the domain average. Both exceptions suggest that, a more complete explanation of the causes shaping the spatial patterns of mortality, such explanation would need to include non-climatic factors, such as biologic, socioeconomic or cultural factors.
\end{abstract}

Keywords: influenza, pneumonia, climate patterns, respiratory diseases

\title{
Introducción
}

La neumonía es una entidad clínica que se caracteriza por la inundación las cavidades alveolares del segmento inferior del sistema respiratorio con un líquido viscoso que contiene numerosas células inflamatorias, detritos celulares y abundantes proteínas (Davis et al., 2012: 364; McCullers, 2006: 572; Morens, Taubenberger y Fauci, 2008: 962). Esto dificulta el proceso de difusión de oxígeno al grado de causar frecuente- 
mente la muerte. En México la mortalidad por infecciones del sistema respiratorio inferior ocupa la novena causa de muerte (Institute of Health Metrics and Evaluation, 2020).

Las causas de neumonía son múltiples y se le puede considerar como una respuesta en común a numerosos procesos de enfermedad. La enfermedad puede ocurrir en cualquier edad y en cualquier mes del año, pero presenta una clara predominancia estacional durante otoño-invierno y afecta con más frecuencia y mayor letalidad a los niños menores de 5 años y adultos con más de 65 años. Aunque las neumonías más frecuentes están asociadas a agentes infecciosos (virus, bacterias y hongos), la más común es la causada por bacterias, principalmente Streptococcus pneumoniae (Fernandes-Matano et al., 2017: 1; Wong-Chew et al., 2017: 32).

La influenza es una enfermedad de origen infeccioso del aparato respiratorio causada por virus de la familia Orthomyxoviridae que a su vez se clasifica en tres grupos: A, B y C. El virus tipo A es el que causa la enfermedad más severa y letal en humanos. Los virus de influenza causan brotes epidémicos anuales durante otoñoinvierno con mayor mortalidad en los grupos de edad de menores de 5 años y mayores de 65. Los virus recombinantes nuevos causan eventos pandémicos globales, después de lo cual el virus nuevo toma la estacionalidad anual normal (Petrova y Russel, 2018: 47).

La estrecha relación epidemiológica entre neumonía e influenza es bien conocida (Shrestha et al., 2015: 15314; Cawcutt y Kalil, 2017: 385). Ambas enfermedades son causas principales de mortalidad por enfermedades respiratorias estacionales; otoñoinvierno (Kuri-Morales, Galván, Cravioto, Zárraga-Rosas y Tapia-Conyer, 2006: 379), afectan a los mismos grupos de edad (menores de 5 años y mayores de 65 años) y son trasmitidas por vía directa (aerosoles) e indirecta por contacto con secreciones respiratorias (Davis et al., 2012; Morens et al., 2008; Rudan, Boschi-Pinto, Biloglav, Mulholland y Campbell, 2008: 408). El aspecto central de esta relación es que en muchos casos influenza y neumonía afectan al mismo individuo, comúnmente primero la influenza y después la neumonía, de hecho, la infección por influenza aumenta la probabilidad de neumonía secundaria 100 veces (Shrestha et al., 2013: 191ra84). Esto se traduce en que aproximadamente el $20 \%$ del total de mortalidad por neumonía adquirida en comunidad ocurre cuando el virus de la influenza precede a la neumonía bacteriana (Davis et al., 2012). En la actualidad la Organización Mundial de la Salud trata a la influenza y la neumonía por separado (Organización Mundial de la Salud [OMS], 2018a; OMS, 2018b). Con base en ello, este estudio trata conjuntamente ambas enfermedades, pero se refiere a ellas como dos enfermedades diferentes.

El binomio influenza-neumonía tiene un alto potencial de causar muerte humana; ello ha quedado particularmente manifestado a escalas globales durante diversos periodos de influenza pandémica en el pasado (Chowell y Viboud, 2016: 13557; Morens y Taubenberger 2018a: 2285; Morens y Taubenberger 2018b: 1453; Longini, Halloran, Nizam y Yang, 2004: 623; Johnson y Mueller 2002: 105) y, actualmente en 2020 por 
Covid-19 (OMS, 2019). Fuera de eventos pandémicos, la influenza-neumonía en la salud humana a nivel mundial es preocupante ya que ocupa el cuarto lugar entre las causas de muerte en el mundo y es el primer lugar en mortalidad infantil por agentes infecciosos (OMS, 2013). En particular, la neumonía está entre las causas de muerte más importantes; por ejemplo, la Global Burden of Desease (GDB) mencionó que, en el año 2015, la neumonía fue la causa de muerte de aproximadamente 2.74 millones de personas (GBD, 2015: 1133).

Un caso relevante para México ocurrió en 1918 durante la pandemia denominada influenza española, que diezmó la población del país y del mundo con un total de 20 millones de muertes (Chowell, Viboud, Simonsen, Miller y Acuna-Soto, 2011: 6; Morens et al., 2008). Es preocupante que la magnitud de la tragedia en México de aquella época permanece todavía sin cuantificar, y es aún más preocupante que no existe información sobre las condiciones en las que ocurrió. Estos eventos resaltan la necesidad de un diagnóstico geográfico detallado de las causas detrás de la mortalidad por influenza-neumonía en México.

En cuanto a causas geográfico-climáticas, diversos estudios han mostrado que las altas ocurrencias de influenza-neumonía están asociadas, en general, a la proliferación de virus y bacterias en condiciones tanto de temperaturas medioambientales como de contenidos de humedad bajos. En una atmósfera seca, las partículas suspendidas en el aire son pequeñas, alcanzan mayores distancias suspendidas en el aire, y penetran la faringe más profundamente (Shaman y Kohn, 2009: 3243; Shaman, Pitzer, Viboud, Grenfell y Lipsitch, 2010: 3243). En estas condiciones, la amenaza viral se hace potencialmente más abundante e incisiva.

Dado que el clima puede actuar como un modulador en la transmisibilidad de los patógenos de influenza y neumonía, se espera que la estacionalidad del clima también module la ocurrencia de ambas enfermedades. De hecho, es conocido que en México y Estados Unidos - incluso en otras regiones (Murdoch, Mitra, Lambert y Erbas, 2014: 30-31) — ambas enfermedades ocurren predominantemente en la temporada más fría (Chang et al., 2016: 486; Cilloniz et al., 2017: 778; Ruiz-Matus, Kuri-Morales y NarroRobles, 2017: 206). Sin embargo, cabe señalar que otros estudios para regiones cálidas y húmedas han demostrado que la estacionalidad de ambas enfermedades no siempre ocurre en la temporada fría (Alonso et al., 2012: 4-7).

\section{Problema y objetivos}

Dada la documentada relación del clima con la ocurrencia de la influenza y la neumonía para distintas regiones del mundo, suponemos que existe una relación similar para México. Sin embargo, esta relación aún no ha sido documentada. La ausencia de tal diagnóstico no es sorprendente si se considera la dificultad de caracterizar fielmente la ocurrencia de influenza y neumonía. Por ejemplo, no es fácil distinguir casos agudos 
de bronquitis y bronquiolitis de casos de influenza y neumonía, por lo que, la información disponible puede sobre representar los casos reales, e incluso, para el caso específico de mortalidad por influenza previo al 2006, los casos podrían no tener la confiabilidad ideal (Ruiz-Matus et al., 2017).

Dadas las dificultades observacionales alrededor de la caracterización cuantitativa de la ocurrencia de influenza y neumonía, este estudio se enfocó a investigar solo la mortalidad. Este parámetro es más objetivo comparado con la severidad o frecuencia de aflicción. En particular, este estudio se planteó el objetivo de diagnosticar la posible relación del clima con la mortalidad por influenza y neumonía en sus aspectos más elementales, utilizando registros asequibles, con la mayor duración posible para disponer de series largas de observaciones. Los aspectos más elementales para diagnosticar respecto a dicha relación fueron tres: sus tendencias, su estacionalidad y sus patrones espaciales. También, nos enfocamos en el diagnóstico de la mortalidad sobre la Macrorregión del Centro de México (95W a 107W, y $18.5 \mathrm{~N}$ a $23 \mathrm{~N}$ ) debido a que cuenta con suficiente información sanitaria, y con un alto potencial por su elevado número de habitantes y densidad poblacional.

\section{Área de estudio}

Según el censo del Instituto Nacional de Estadística y Geografía (INEGI, 2010), en la Macrorregión del Centro de México vive poco más del 60\% de la población nacional, e incluye regiones donde la densidad poblacional llega a ser hasta 5,960 hab/

$\mathrm{km}^{2}$. El clima es típicamente continental monzónico, pero alberga una gran variedad subtipos climáticos (García, 2004: 43) debido a su orografía accidentada. Los elementos fisiográficos importantes de esta región, entre otros, son la Sierra Madre Occidental, la Sierra Madre Oriental y el Altiplano Central. Mientras que el Altiplano Central es típicamente frío y seco durante el invierno, las vertientes costeras de las sierras son cálidas y húmedas todo el año (Ribot, Magalhães y Panagides, 2005: 55-70).

\section{Datos}

Los datos de mortalidad por influenza y neumonía fueron obtenidos de la página del Sistema Nacional de Información en Salud (SINAIS, 2018). Estos datos provienen de los certificados de defunción de las oficinas de Registro Civil de cada municipio y cubren el periodo 1979-2015. Para el periodo 1979-1997, los casos de neumonía corresponden a las claves 480 a 486 de la Clasificación Internacional de Enfermedades 9 (CIE-9); los de influenza corresponden a la clave 487. Para el periodo 1998-2015, bajo la CIE-10, los casos de neumonía corresponden a las claves J12 a J18, y los de 
influenza a las claves J10 y J11. Los datos de número de habitantes municipales fueron obtenidos de los censos nacionales ${ }^{1}$ de 1970 a 2010 (INEGI, 2010).

Los datos de temperatura $(T)$ y presión de vapor de agua ${ }^{2}(e d)$ media mensual a 2 m de la superficie, fueron tomados de la base Climate Research Unit TS4.01 de la Universidad de East Anglia (CRU TS4.01). La resolución espacial de las variables ocupadas es $0.5^{\circ} \mathrm{X} 0.5^{\circ}$; esta resolución, equivale aproximadamente a cuadros de malla de $55.5 \mathrm{~km}^{2}$ (aprox. $111.12 \mathrm{~km}$ de longitud por $111.32 \mathrm{~km}$ de latitud). Se ocupó esta base datos, no por su resolución espacial, sino por los procesos de control de calidad y de asimilación de datos que la respaldan. Ambos procesos usan distintas fuentes de información; para México, las observaciones del Servicio Meteorológico Nacional constituyen una de sus fuentes de información procesadas (e. g., Harris et al., 2014: 623; New, Hulme y Jones, 1999: 831). La resolución temporal la base de datos de CRU es mensual, y aunque cubre el periodo 1901-2016, solo se ocuparon los datos de 1979-2015.

\section{Metodología}

En términos generales, la metodología se dividió en dos partes; en la primera se homogeneizó la resolución espacial y temporal de los datos, y en la segunda se calcularon tasas y promedios estacionales ${ }^{3}$. Los datos de población fueron extrapolados linealmente para cubrir el periodo 2010-2015. Después, el conjunto de datos de población (1979-2015) fue interpolado linealmente a una resolución mensual. Ambos procedimientos fueron aplicados a nivel municipal y en ambos procedimientos se usó el método de mínimos cuadrados. Este método garantizó mantener fielmente el comportamiento claramente lineal observado en toda la macrorregión (Fig. 1c).

Posteriormente, los datos municipales de población y mortalidad fueron agrupados en rejillas espaciales regulares de $0.25^{\circ} \mathrm{X} 0.25^{\circ}$ usando el método de binning. Después, para cada rejilla, se calcularon las tasas de mortalidad (por cada 100 mil hab.) anuales y estacionales para invierno (diciembre-febrero), primavera (marzo-mayo), verano (junio-agosto) y otoño (septiembre-noviembre). Finalmente, los datos de $T$ y ed también fueron promediados anual y estacionalmente.

\footnotetext{
${ }^{1}$ No se usaron los datos de los conteos rápidos por facilidad y por homogeneidad de procesamiento.

${ }^{2}$ Una descripción completa del uso de ed como medida de la humedad en meteorología y en climatología puede ser consultado en Stull (2017: 87).

${ }^{3}$ Los programas computacionales C-shell (https://en.wikipedia.org/wiki/C_shell) y Matlab (https:// www.mathworks.com/products/matlab.html) se utilizaron para cálculos matemáticos y estadísticos, y el programa Generic Mapping Tools (https://www.generic-mapping-tools.org/) se utilizó para la creación de todas las imágenes. El código fuente detrás de tales procedimientos puede ser distribuido bajo pedidos específicos.
} 
a)

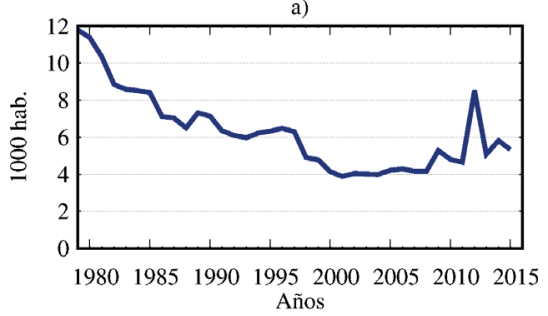

b)

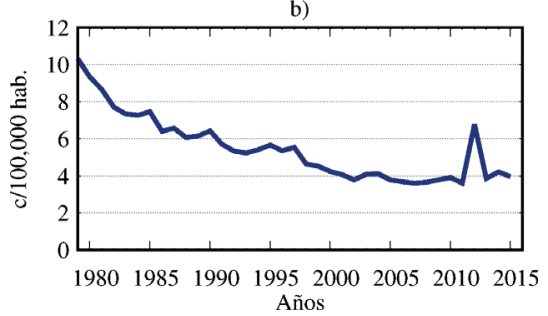

c)

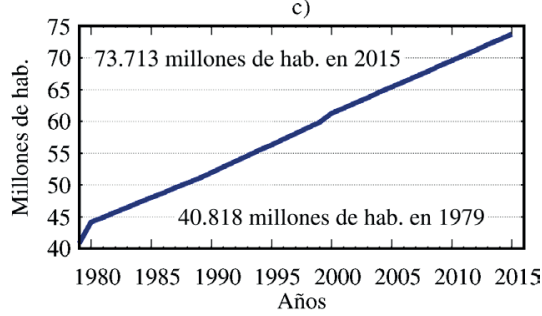

d)

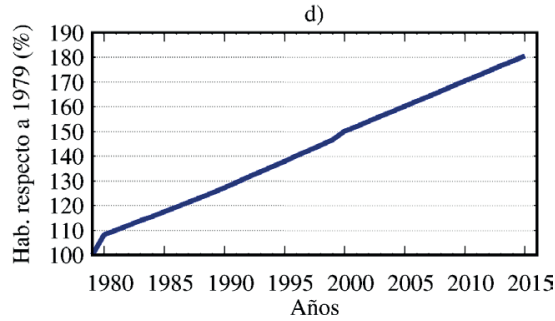

Figura 1. Evolución de la mortalidad por influenza y neumonía de 1979 a 2015 de la Macrorregión del Centro de México en (a) números totales, (b) tasas (cada 100 mil habitantes), (c) en números totales de habitantes y (d) porcentaje de habitantes respecto a los de 1979. Fuente: Elaborada por los autores a partir de SINAIS (2018).

\section{Resultados}

\section{Tendencias de mortalidad}

El periodo de estudio (1979-2015) se caracteriza por presentar una tendencia negativa de mortalidad por influenza y neumonía, y una tendencia positiva en el número de habitantes (Fig. 1). Por un lado, la población inicial en la Macrorregión del Centro de México pasó de 33 millones en 1979 a 73 millones en 2015. Respecto a la población de 1979, tal incremento al 2015 corresponde a 80\% (40 millones; Fig. 1d). La mortalidad disminuyó de 12 mil muertes en 1979 a cerca de 4 mil en 2000 (Fig. 1a), es decir que la tasa de mortalidad paso de 10 a 4 muertes por cada 100 mil habitantes (Fig. 1b). Aunque en términos generales existe una tendencia negativa entre 1979 y 2015, las tasas de mortalidad entre 2000 al 2015 fueron prácticamente nulas y ligeramente positivas en números totales.

\section{Patrones espaciales de mortalidad}

La distribución espacial de la mortalidad por influenza y neumonía en la Macrorregión del Centro de México está mayormente definida por la ubicación de las ciudades más pobladas, ya que en ellas se localiza por un lado, la mayor mortalidad en números totales, 
y por otro, la mortalidad más baja en tasas. La Fig. 2 muestra la distribución espacial de la población en la Macrorregión del Centro de México y de la mortalidad promedio por influenza-neumonía en el periodo 1979-2015. Se puede notar que la mayor parte las defunciones (Fig. 2b) se encuentran en las regiones más pobladas (Fig. 2a): principalmente sobre la Ciudad de México, Guadalajara, y Puebla. La explicación a esto es simple: en cuanto al números totales de casos, a mayor número de habitantes, mayor mortalidad.

Por otro lado, en términos de tasas, la Fig. 2c revela que las tasas de mortalidad por influenza y neumonía tienden a ser más bajas en regiones con más habitantes respecto a regiones con menos habitadas. El caso más evidente es el de la Ciudad de México: allí, la tasa de mortalidad, de aproximadamente 8 personas por cada $100 \mathrm{mil}$ hab., es un mínimo relativo con respecto a las regiones a su alrededor. Otro ejemplo se puede observar en la región de la ciudad de Guadalajara, Jalisco, también con una tasa de mortalidad de aproximadamente 8 personas de cada 100 mil habitantes (Fig. 2c). Este comportamiento se cuantifica en la Fig. 3, la cual relaciona el número de habitantes con la mortalidad. Después del umbral aproximado de un millón de hab. por cada $770 \mathrm{~km}^{2}$ (por punto de malla), las tasas de mortalidad no superan 10 personas por cada 100 mil hab.

Se calculó la media de las tasas de mortalidad de todo el dominio con el propósito de ubicar las regiones con mortalidad relativamente alta o baja en la Macrorregión del estudio. El valor promedio de la tasa de mortalidad es de 16 por cada 100 mil hab. Los resultados muestran que las tasas de mortalidad más altas se ubican en Tlaxcala, Hidalgo, Puebla, el sur de San Luis Potosí y en la región del Estado de México (Fig. 4). Por otro lado, las tasas de mortalidad son relativamente más bajas en la Ciudad de México, Aguascalientes, Colima, Michoacán, Centro y norte de Veracruz y en prácticamente todo el estado de Nayarit. Los estados de Querétaro, Jalisco y Guanajuato no sobresalen respecto a los anteriores estados.

Con los resultados obtenidos puede decirse que, las regiones con relativamente baja mortalidad por influenza y neumonía (número de muertes), en primera instancia se pueden explicar por los patrones demográficos (Figs. 1-4): ya sea porque la población es baja (hay pocos fallecimientos porque hay pocas personas) o porque su densidad poblacional es alta (ciudades de México, Guadalajara y Puebla). Ahora bien, los patrones climáticos pueden analizarse como una posible segunda instancia para entender mejor los patrones de mortalidad (Fig. 4). Esto se explora a continuación.

\section{Relación entre los patrones de mortalidad con los patrones climáticos}

La relación principal encontrada respecto a patrones de mortalidad y patrones climáticos es que la mortalidad es más alta en regiones relativamente frías y secas; esto se muestra al comparar los patrones de mortalidad por influenza y neumonía de la Fig. 3c con los valores estacionales promedio de $T$ y ed de las Figs. 5 a y 5 b. Dicha relación es 
a)

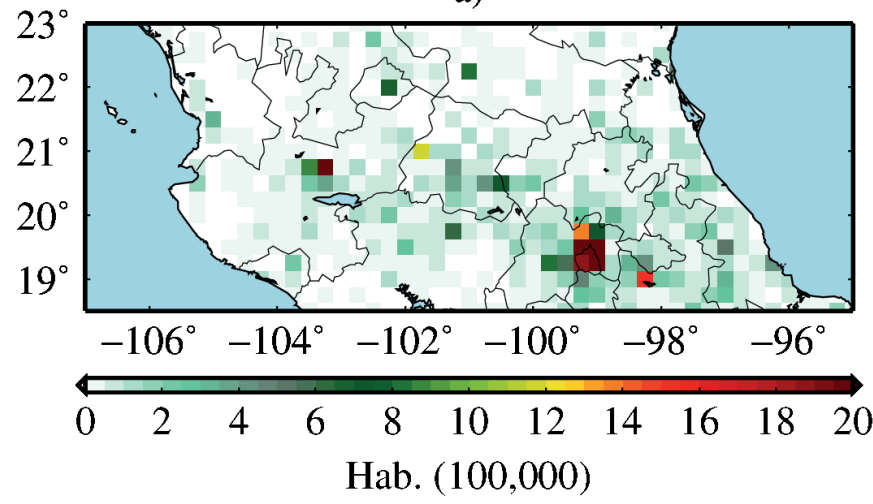

b)

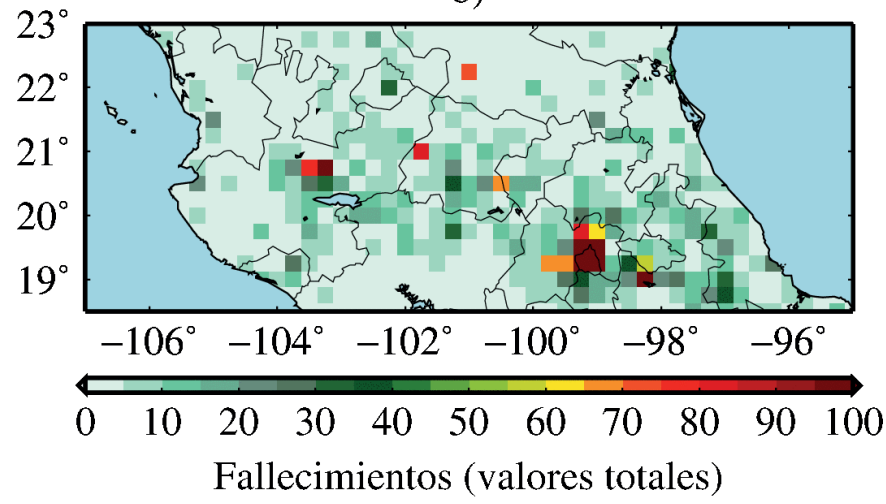

c)

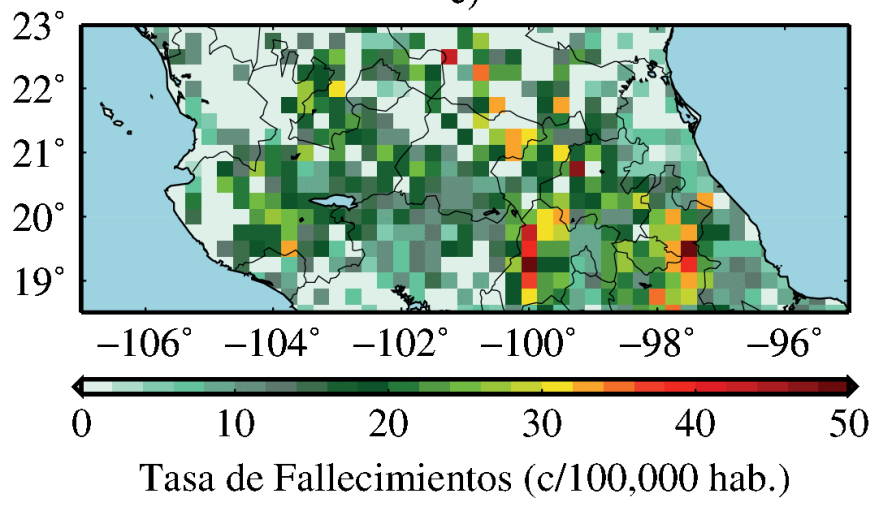

Figura 2. Promedios anuales de mortalidad por influenza y neumonía de 1979 a 2015 para la Macrorregión del Centro de México como (a) número de habitantes, (b) valores totales y (c) valores en tasas. Fuente: Elaborada por los autores a partir de SINAIS (2018). 


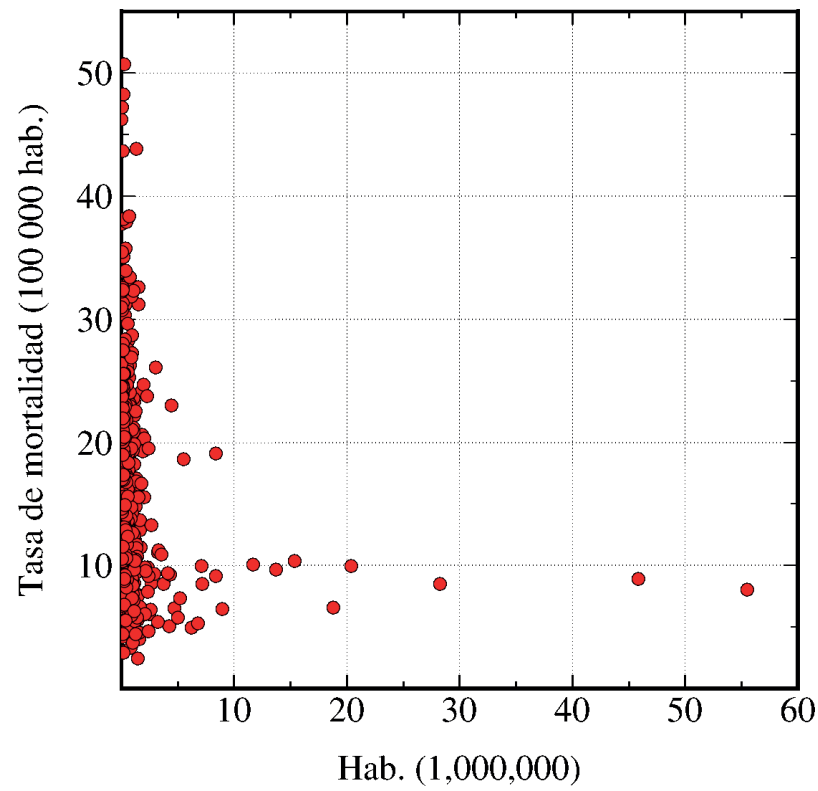

Figura 3. Correspondencia entre mortalidad por influenza y neumonía (en tasas por cada 100 mil hab.), y población (en millones de hab.) para la Macrorregión del Centro de México con datos promediados del periodo 1979-2015. Fuente: Elaborada por los autores a partir de SINAIS (2018) e INEGI (2015).

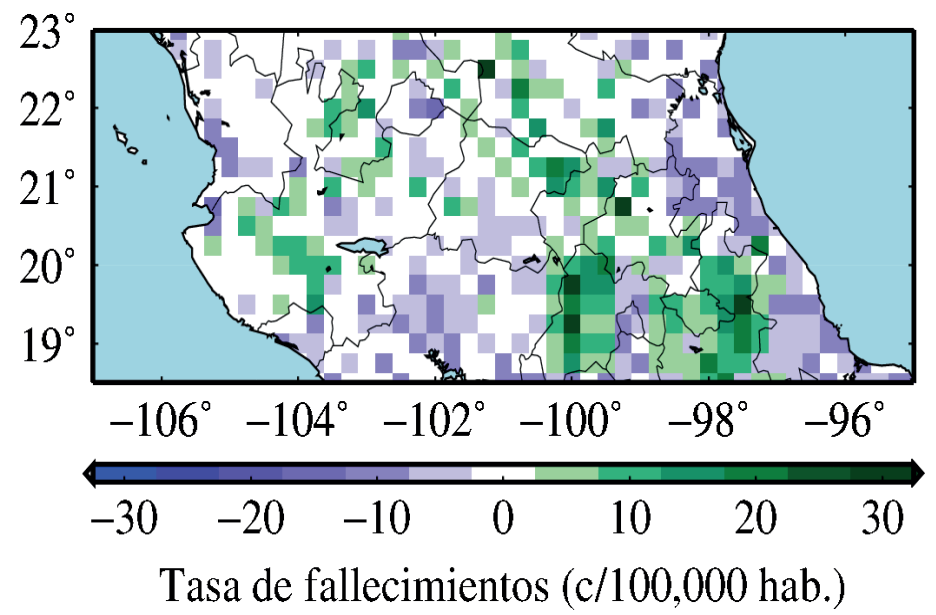

Figura 4. Promedios anuales (1979-2015) de mortalidad en tasas (por cada 100 mil habitantes) por influenza y neumonía mostrada como valores de anomalías respecto a la media de todo el dominio: 16 por cada 100 mil habitantes. Fuente: Elaborada por los autores a partir de SINAIS (2018) e INEGI (2015). 

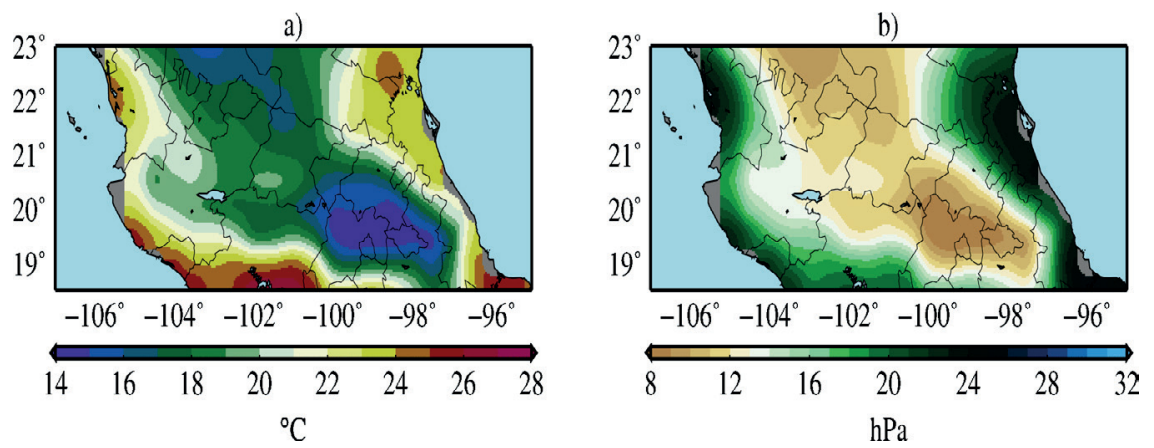

Figura 5. Promedios anuales de (a) temperatura y (b) presión de vapor de agua del periodo 1979-2015. Fuente: Elaborada por los autores a partir de CRU (2019).

simplificada en la Fig. 6, que muestra isolíneas de $T$ y ed con valores representativos sobre las regiones donde la mortalidad es más pronunciada. En particular, la región del Altiplano Central tiene los valores de $T$ y ed más bajos de todo el dominio estudiado y los más altos respecto a las tasas de mortalidad. Esta región incluye el poniente del Estado de México y los estados de Tlaxcala y Puebla. En estos estados, $T$ y ed tienen los valores más bajos de toda la macrorregión: $T$ oscila entre $16{ }^{\circ} \mathrm{C}$ y $20^{\circ} \mathrm{C}$ (Fig. 6a), y $T$ y ed es, en general, menor a $10 \mathrm{hPa}$ (Fig. 6b). Otra región con alta mortalidad, pero con valores de $T$ y ed menos fríos y secos $\left(20^{\circ} \mathrm{C}\right.$ y $16 \mathrm{hPa}$; Fig. 6) son las zonas de sotavento de la Sierra Madre Occidental y de la Sierra Madre Oriental (Fig. 6). Esta región se caracteriza por una orografía accidentada, con un gradiente altitudinal pronunciado (las curvas de elevación de 1,000 m y 2,000 m se encuentran cercanas; Fig. 7), y con patrones sinuosos (cf. línea café y en amarillo en Fig. 7).

\section{Estacionalidad}

Las variaciones estacionales de mortalidad por influenza y neumonía muestran dos aspectos importantes: primero, los patrones espaciales de mortalidad son casi constantes en primavera, verano y otoño (Fig. 8) y segundo, durante el invierno se registra un máximo relativo (Fig. 8a). Este resultado es consistente con diferentes estudios previos que muestran los máximos de contagio y mortalidad tanto de influenza como de neumonía en invierno (Cilloniz et al., 2017; Ruiz-Matus et al., 2017; Shaman y Kohn, 2009). Ambos resultados sugieren que, aunque las variaciones estacionales de mortalidad por influenza y neumonía son relativamente pequeñas (con tasas entre 0 y 5 muertes por cada 100 mil hab.), durante la estación más fría y seca de invierno la mortalidad tiende a incrementarse (Ribot et al., 2005). Cabe señalar que durante las cuatro estaciones persiste la mortalidad en el poniente del Estado de México, Puebla, Tlaxcala, Guanajuato, Querétaro, norte de Colima, sur y norte de Jalisco y sur de San Luis Potosí. 

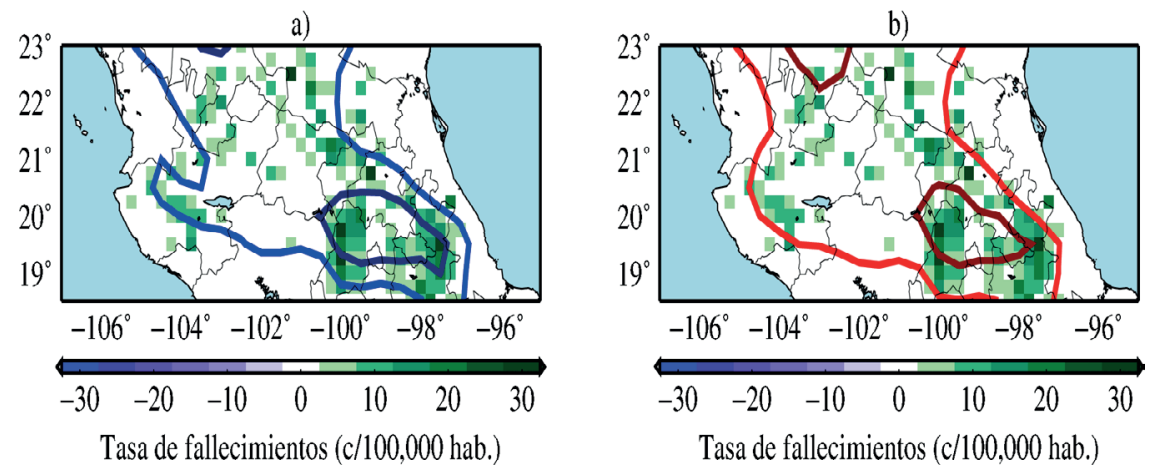

Figura 6. Tasas de mortalidad por influenza y neumonía sobre regiones donde la mortalidad excede el promedio de la macrorregión del Centro de México (16 por cada 100 mil hab.) y su relación con (a) las isotermas medias anuales de $20^{\circ} \mathrm{C}$ (en azul) $16^{\circ} \mathrm{C}$ (en azul oscuro) y con (b) las isobaras de presión de vapor de agua de $16 \mathrm{hPa}$ (en rojo) y $10 \mathrm{hPa}$ (en rojo oscuro).

Fuentes: Elaborada por los autores a partir de CRU (2019) y SINAIS (2018).

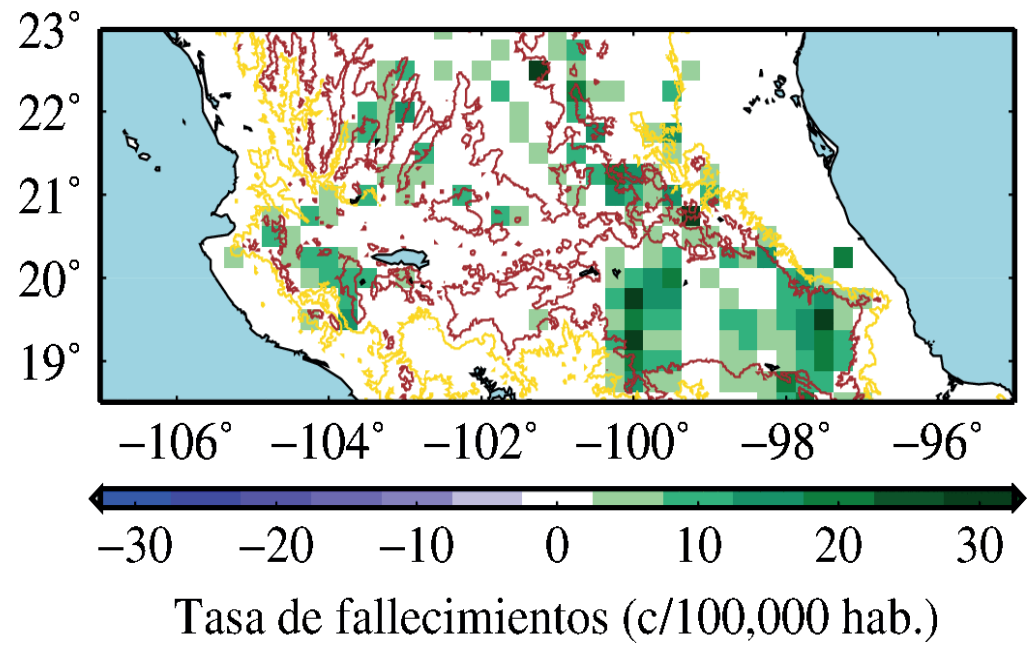

Figura 7. Tasas de mortalidad por influenza y neumonía sobre regiones donde la mortalidad excede el promedio de la Macrorregión del Centro de México (16 por cada 100 mil habitantes). Las curvas de nivel de 1,000 m s. n. m. (en amarillo) y 2,000 m s. n. m. (en marrón) también son mostradas. Fuentes: Elaborada por los autores a partir de SINAIS (2019) y

Amante y Eakins (2008). 
a)

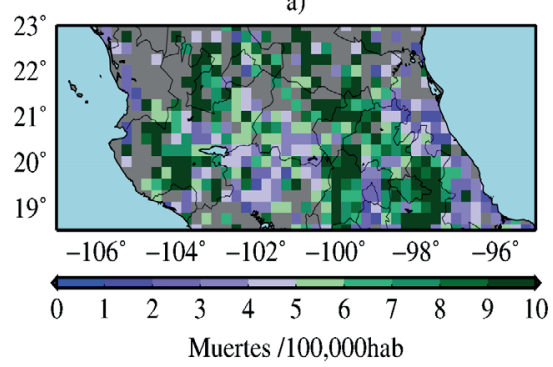

b)

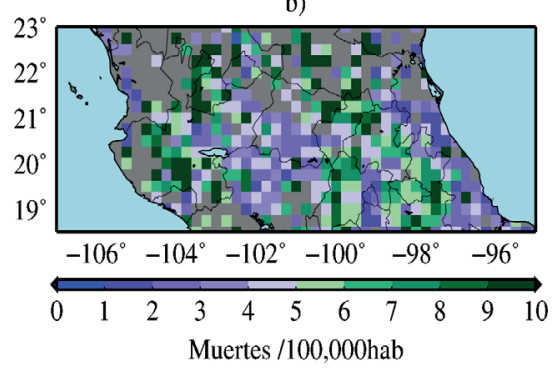

c)

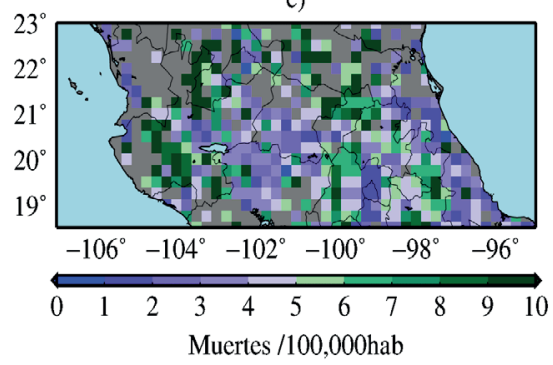

d)

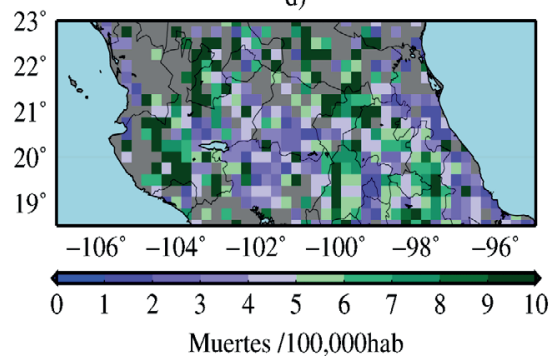

e)

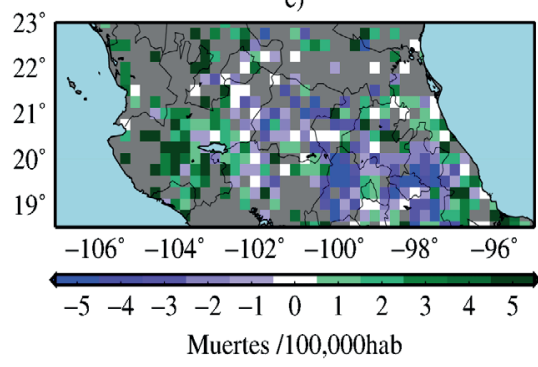

f)

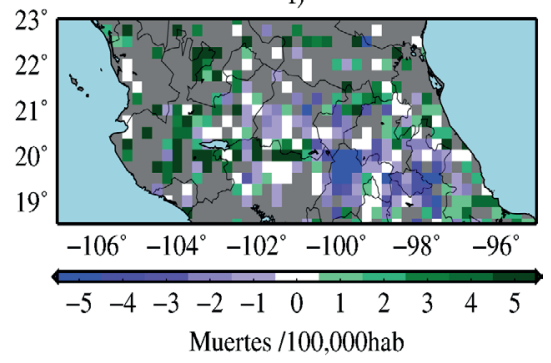

g)

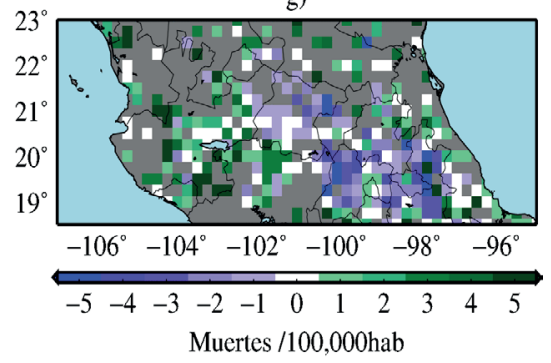

h)

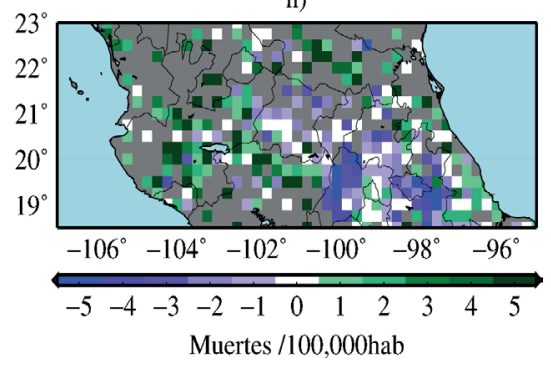

Figura 8. Tasas de mortalidad estacional por influenza y neumonía en (a-d) promedio para el periodo 1979-2015, y como (e-h) anomalías del año 2012; en ambos casos se muestran las estaciones de (a, e) invierno, (b, f) otoño, (c, g) verano y (d, h) primavera. Fuente: Elaborada por los autores a partir de SINAIS (2018). 


\section{Un año con alta mortalidad}

Ya que los resultados hasta esta sección han mostrado una relación espacial repetitiva (sobre regiones más frías y secas tiende a haber mayor mortalidad por influenza y neumonía), es razonable suponer que esta relación puede ser extrapolada para entender anomalías anuales. Por ello nos enfocamos en el año 2012, un año con extremadamente alta mortalidad (Figs. 1 a y b). El promedio de muertes anuales para la Macrorregión del Centro de México del 2000 al 2015 fue de 4,777 personas con una tasa de mortalidad de 4 personas por 100 mil habitantes, pero en el 2012 se registraron 8,519 por influenza o neumonía con una tasa de casi 7 personas por cada 100 mil habitantes (Figs. 1 a y b). El patrón espacial de mortalidad por influenza y neumonía en 2012 (Figs. 8 e-h) tuvo una característica diferente al promedio de mortalidad: en el 2012 ocurrió una tendencia contraria con valores relativamente altos cerca de las costas del Océano Pacífico (en los estados de Michoacán y Jalisco) y del Golfo de México (Veracruz), en gran parte de San Luis Potosí y en el sur de Zacatecas (normalmente la región Altiplano presenta valores más altos que sus alrededores; Fig. 7). Este patrón tuvo su máximo durante la estación de invierno, pero su distribución espacial se repitió durante las otras estaciones. ¿La alta mortalidad del 2012 pudo estar relacionada al clima?

Si condiciones anómalamente frías y secas ocurrieron sobre las regiones con más mortalidad durante en el 2012, el clima podría ser considerado como una posible causa de la mortalidad del 2012. Sin embargo, las condiciones climáticas no fueron ni anómalamente frías, ni anómalamente secas sobre las regiones con más mortalidad (Fig. 9). Incluso, este año fue un año promedio en cuanto humedad, pero fue anómalamente cálido. Estos resultados indican que, a grandes rasgos, sin dividir la mortalidad por grupos poblacionales (edad y género), la gran mortalidad del 2012 no puede ser explicada por las bajas temperaturas y bajos contenidos de humedad estacionales. Definitivamente, estos resultados son un ejemplo de la necesidad de más estudios respecto a los detalles espaciales, geográficos, y demográficos para entender patrones clave en la dinámica de la mortalidad por influenza y neumonía básica en México.

Por otro lado, causas biológicas asociadas a la alta mortalidad del 2012 son claras (patógenos), y han sido documentadas por diversos estudios, en particular, el virus tipo AH1N1 (Hajjar y McIntosh, 2010: 2; Reyes Canche-Pech et al., 2017: 2). De hecho, al periodo invierno 2012-invierno 2014 se le ha considerado la cuarta onda causada por el virus A (H1N1) pdm09 de la pandemia de influenza originada en México en el año 2009 (Borja-Aburto, Chowell y Viboud, 2012: 563; Dávila et al., 2014: 7).

\section{Discusión y conclusiones}

En este estudio se mostraron principalmente dos resultados respecto a la mortalidad por influenza y neumonía para la Macrorregión del Centro de México: sus tendencias temporales, y su distribución geográfico-climática. Ambos resultados responden al 
a)

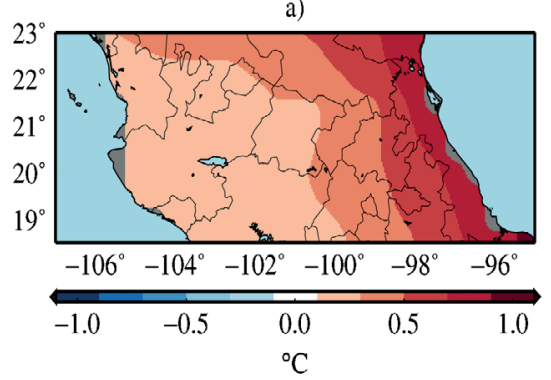

b)

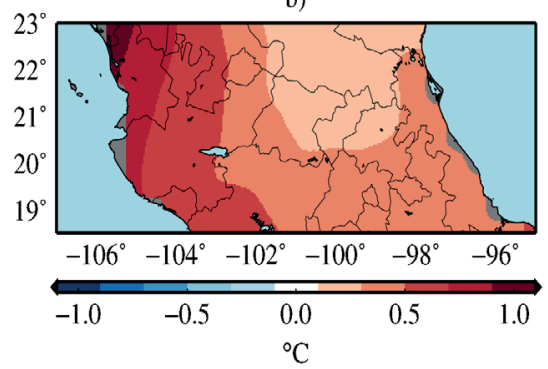

c)

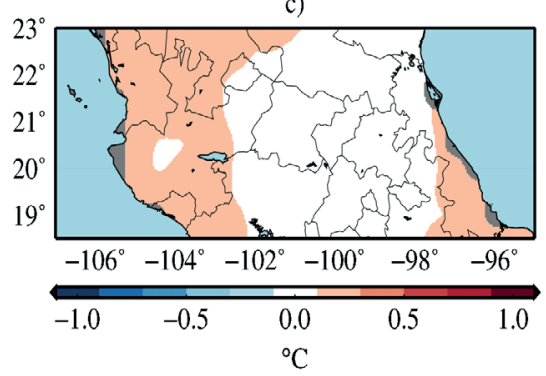

d)

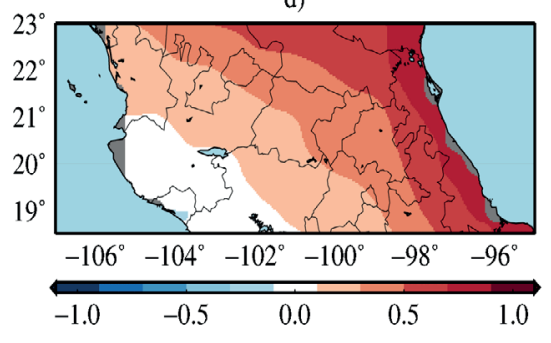

e)

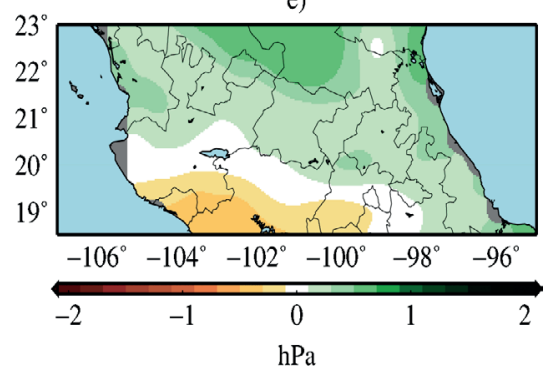

f)

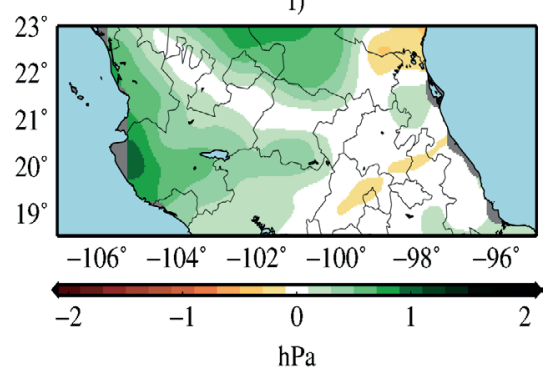

g)

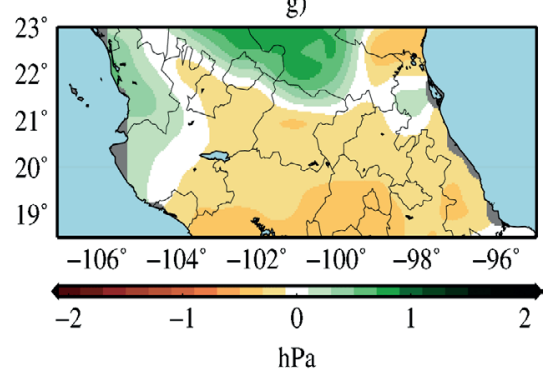

h)

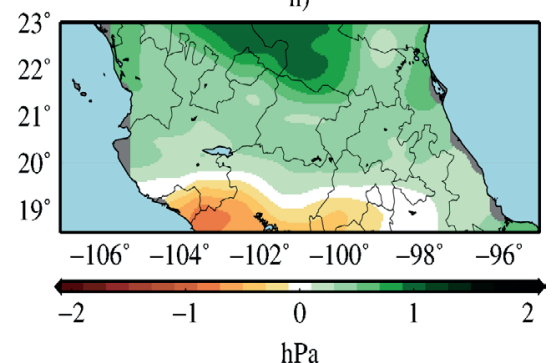

Figura 9: Anomalías de (a-d) temperatura (en $\left.{ }^{\circ} \mathrm{C}\right)$ y (e-h) presión de vapor de agua (en hPa) del año 2012 durante $(\mathrm{a}, \mathrm{e})$ invierno $(\mathrm{b}, \mathrm{f})$ otoño $(\mathrm{c}, \mathrm{g})$ verano y $(\mathrm{d}, \mathrm{h})$ primavera. Fuente: Elaborada por los autores a partir de CRU (2019). 


\section{$112 \square$ MORTALIDAD POR INFLUENZA Y NEUMONÍA EN LA MACRORREGIÓN DEL CENTRO}

objetivo primario de este estudio, diagnosticar la posible relación del clima con la mortalidad por influenza y neumonía en sus aspectos más elementales. Nuestros resultados mostraron aspectos geográfico-climáticos de la ocurrencia de la influenza y la neumonía que no habían sido documentados anteriormente para México, sin embargo, como se explica en los siguientes párrafos, la necesidad de estudios multidisciplinarios es latente, ya que el problema es complejo y claramente multifactorial.

Respecto a las tendencias, los resultados mostraron que en las últimas décadas la mortalidad ha disminuido. Específicamente, en el año 1979 se registraban cerca de 8 mil muertes, pero cerca del año 2000 se registraban casi la mitad de estas, cerca de 4 mil. Lo sorprendente de este resultado es que, la tendencia negativa no solo se manifiesta en números absolutos de habitantes, también se manifiesta en tasas de mortalidad. Es decir, a pesar de que la población en el Centro de México creció (se incrementó en casi un millón de habitantes por año desde 1979) la mortalidad disminuyó. Estas tendencias son consistentes con datos presentados por otros estudios (Fernández-Cantón y Perdón Villaseñor, 2009; McAllister et al., 2019: 53-57) los cuales han demostrado con diferentes fuentes de información que, en muchas regiones del mundo, la mortalidad por neumonía ha descendido progresivamente en todos los grupos de edad durante las últimas cinco décadas. A pesar de dicha consistencia, las tendencias negativas que documentamos representan grosso modo a toda la macrorregión, sin embargo, son necesarios estudios con una resolución espacial más fina.

Nuestro diagnóstico de las tendencias documentadas en este estudio coincide con los diagnósticos de estudios previos que han señalado a la vacunación y a su aceptación entre la población como la causa principal del decremento en la mortalidad por influenza y neumonía. Por otro lado, en contraste con las tendencias negativas de 1979 a 2000, las tendencias del 2000 al 2015 fueron prácticamente nulas en términos de tasas e incluso ligeramente positivas en términos de números totales. Estudios previos han sugerido que, para mejorar las tendencias de mortalidad recientes, es necesario enfocar esfuerzos al acceso de la población a los servicios de salud, en las campañas de vacunación (Kuri-Morales et al., 2006), y en la adopción de hábitos saludables que previenen la transmisión de enfermedades virales (Morawska 2006: 9). En términos generales significa la adopción de estrategias que manejen mejor el riesgo ante enfermedades respiratorias. Tales medidas podrían tener una importancia clave en el proceso de adaptación que tenga la población a los posibles impactos que el cambio climático en la incidencia de enfermedades respiratorias en las próximas décadas.

Sin embargo, cabe señalar algunas fuentes de incertidumbre que pueden ser determinantes de las características de las tendencias observadas. Estas fuentes de incertidumbre están asociadas al análisis cuantitativo de la influenza y neumonía con las fuentes de información existentes (Ruiz-Matus et al., 2017). Por ejemplo, es una posibilidad que cambios en la forma de medición hayan afectado los resultados en las tendencias (e. g., cambios en la definición de un caso sospechoso y uno confirmado, o cambios en la disponibilidad y captura de información). Aunque este punto es claramente especulativo, es importante considerarlo al interpretar los resultados mostrados. 
Este punto también ejemplifica la dificultad detrás del problema de la detección y atribución de mortalidad no solo por enfermedades como la influenza y la neumonía, sino por enfermedades respiratorias en general.

Los patrones geográficos de mortalidad por influenza y neumonía mostraron dos zonas con alta mortalidad, la primera de estas regiones es la región del Altiplano Central, la segunda está definida por su orografía accidentada: incluye a las partes montañosas del sotavento de la Sierra Madre Occidental y de la Sierra Madre Oriental. Aunque ambas regiones están a más de $1,000 \mathrm{~m}$ de altura, y sus valores típicos de temperatura y humedad son relativamente fríos y secos, se espera que la dinámica detrás de la mortalidad en estas regiones sea esencialmente diferente. Por ejemplo, la relativamente alta mortalidad sobre la segunda región, por su ubicación sobre regiones montañosas, podría estar mayormente ligada a los niveles relativamente altos de pobreza (Programa de las Naciones Unidas para el Desarrollo [PNUD], 2019: 47). Un diagnóstico respecto a la relación entre pobreza y mortalidad por influenza y neumonía está fuera de los alcances de este estudio. Por otro lado, un diagnóstico preliminar sobre la primera región (el Altiplano Central) es que su alta mortalidad podría estar asociada a dos factores: la densidad poblacional alta, y la transmisibilidad de patógenos alta ocasionada por su clima relativamente frío y seco.

Aunque es importante conocer las causas detrás de los patrones geográficos de mortalidad, tal vez sea más importante conocer qué causa que un año en particular tenga más casos de lo normal, por ejemplo, el 2012. Para este año, los resultados confirmaron dos diagnósticos documentados en este estudio. (1) La mayoría de los casos en números totales se registraron sobre las regiones más pobladas. (2) Las tasas más altas de mortalidad se registraron durante las temporadas con meses más fríos (estaciones de otoño e invierno) (Chang et al., 2016; Cilloniz et al., 2017). Sin embargo, la influencia que tuvieron las anomalías de temperatura y humedad de este año en particular en la alta mortalidad no fue evidente; el 2012 no fue más frío de lo normal, tampoco más seco, pero sí hubo notablemente más muertes por influenza y neumonía. Estos resultados sugieren que condiciones frías y secas pueden ayudar a explicar patrones promedio de la ocurrencia de influenza y neumonía, pero estas condiciones climáticas no necesariamente pueden explicar los patrones anómalos, ni años atípicos o sus tendencias. Una posible explicación de porqué durante el 2012 la mortalidad fue muy alta pero las condiciones climáticas no fueron anormales es que, en ese año, los agentes infecciosos tuvieron una dinámica diferente a la de otros años (Ruiz-Matus et al., 2017). Sin embargo, tal explicación no resuelve la pregunta de qué papel tuvo el clima en ese año. Nuestros resultados, que sugieren un papel relativamente pequeño del clima para ese año, tendrían que ser verificados con más casos de estudio, y otras variables climáticas con mayor resolución temporal y espacial. También, idealmente, un estudio de tal tipo no se limitaría a un diagnóstico de registros de mortalidad, ya que también incluiría registros de casos presentados y su grado de severidad, y el grado de vulnerabilidad humana a las infecciones respiratorias sobre las regiones más afectadas. 


\section{$114 \square$ MORTALIDAD POR INFLUENZA Y NEUMONÍA EN LA MACRORREGIÓN DEL CENTRO}

Otro aspecto de los resultados mostrados que requiere un análisis de vulnerabilidad es que las tasas de mortalidad más bajas en regiones pobladas ocurren notablemente en las ciudades más grandes, como la Ciudad de México y Guadalajara. Idealmente, un análisis de vulnerabilidad para explorar este resultado incluiría un diagnostico respecto a factores socio económicos, políticos y culturales, y biológicos. Sin duda, estos son temas interesantes para posibles investigaciones futuras. Por ejemplo, dentro de los factores socioeconómicos posibles líneas de investigación podrían incluir la movilidad de las personas, estrategias de vacunación y prevención de contagios, o disponibilidad y acceso a cuidados hospitalarios. Por el lado de factores biológicos, posibles líneas de investigación incluirían aspectos relacionados a la dispersión de agentes infecciones y hábitos personales, a la inmunodeficiencia (e. g., secundaria asociada a la desnutrición y falta de lactancia materna en menores de 6 meses de edad), enfermedades crónicas, predisposición a complicaciones severas por inmunocompromiso (e. g., por diabetes o infección por VIH/SIDA), inmunosenescia en la población geriátrica, genética individual y genómica, entre muchos otros factores.

Otro componente importante de la mortalidad por influenza-neumonía que deben de considerar futuros estudios es su caracterización demográfica: ¿Qué grupos poblacionales divididos por edad y género fueron los más afectados? ¿Qué diferencias espaciales existen? ¿Cómo influye el clima, tanto por los valores medios como por eventos extremos? Las respuestas a estas preguntas, junto con los resultados de este estudio, podría ser de ayuda, entre otras cosas, al diseño y optimización de campañas de vacunación por influenza y constituyen las bases para los siguientes estudios de este grupo de trabajo. Es crucial la construcción de una caracterización cuantitativa de la vulnerabilidad a enfermedades respiratorias en México, y en particular, la caracterización de la vulnerabilidad de grupos etarios como infantes y adultos mayores, así como las de personas con enfermedades crónicas como hipertensión, asma, diabetes y enfermedad cardiovascular (Musher y Thorner, 2014: 1627; Bunker et al., 2016: 29). Estos aspectos relativos a la vulnerabilidad de la población a enfermedades respiratorias son de particular relevancia en el contexto de la pandemia de coronavirus desatada en el 2020.

\section{Bibliografía}

Alonso, Wladimir; Laranjeira, Bruno J.; Pereira, Samuel A.; Florencio, Caroline M.; Moreno, Eduardo C.; Miller, Mark A.; Giglio, Ricardo; Schuk-Paim, Cynthia; y Moura, Fernanda E. A. (2012). "Comparative Dynamics, Morbidity and Mortality Burden of Pediatric Viral Respiratory Infections in an Equatorial City". The Pediatric Infectious Disease Journal, 31(1), e9-e14. doi.org/10.1097\%2FINF.0b 013e31823883be

Amante, Christopher; y Eakins, Barry W. (2008). "ETOPO1 1 Arc-minute Global Relief Model: Procedures, Data Sources and Analysis". NOAA Technical Memo- 
randum NESDIS NGDC-24. National Geophysical Data Center, NOAA. doi. org/10.7289/V5C8276M

Borja-Aburto, Victor Hugo; Chowell, Gerardo; Viboud, Cécile; Simonsen, Lone; Miller, Mark A.; Grajales-MuñIz, Concepción; GOnZÁlez-Bonilla, Cesar R.; Diaz-Quiñones, Jose A; y EchevarRía-Zuno, Santiago. (2012). "Epidemiological Characterization of a Fourth Wave of Pandemic A/H1N1 Influenza in Mexico, Winter 2011-2012: Age Shift and Severity". Archives of Medical Research, 43(7), 563-570. doi.org/10.1016/j.arcmed.2012.09.005

Bunker; Aditi; Wildenhain, Jan; Vandenbergh, Alina; Henschre, Nicholas; Rocklöv, Joacim; HaJAT, Shakoor; y SAUERBorn, Rainer. (2016). "Effects of Air Temperature on Climate-sensitive Mortality and Morbidity Outcomes in the Elderly; A Systematic Review and Meta-analysis of Epidemiological Evidence". EbioMedicine, 6, 258-268. doi.org/10.1016/j.ebiom.2016.02.034

Cawcutt, Kelly; y Kalit, Andre C. (2017). "Pneumonia with Bacterial and Viral Coinfection". Current Opinion on Critical Care, 23(5), 385-390. doi.org/10.1097/ MCC. 0000000000000435

Chang, D. H.; Bednarczyk, Robert A.; Becker, Edmund R.; Hockenberry, Jason M.; Weiss, Paul S.; Orenstein, Walter A.; y Omer, Saad B. (2016). "Trends in U. S. Hospitalizations and Inpatient Deaths from Pneumonia and Influenza, 1996-2011". Vaccine, 34(4), 486-494. doi.org/10.1016/j.vaccine.2015.12.003

Chowell, Gerardo; y Viboud, Cécile. (2016). "Pandemic Influenza and Socioeconomic Disparities: Lessons from 1918 Chicago". Proceedings of the National Academy of Science of the United States of America, 113(48), 13557-13559. doi.org/10.1073/ pnas. 1616537113

Chowell, Gerardo; Viboud, Cécile; Simonsen, Lone; Miller, Mark A.; y Acuna-Soto; Rodolfo. (2011). "Mortality Patterns Associated with the 1918 Influenza Pandemic in Mexico: Evidence for a Spring Herald Wave and Lack of Preexisting Immunity in Older Populations". The Journal of Infectious Diseases, 202(4), 567-575. doi.org/10.1086/654897

Cilloniz, Catia; Ewig, Santiago; Gabarrus, Albert; Ferrer, Miquel; Puig de la Bella CASA, Jorge; Mensa, Josep; y Torres, Antoni. (2017). "Seasonality of Pathogens Causing Community-acquired Pneumonia". Respirology, 22(4), 778-785. doi. org/10.1111/resp. 12978

Clasificación Internacional De Enfermedades (CIE). (s.f.). Consultado el 20 de octubre de 2018 en https://www.who.int/classifications/icd/en/

Climate Research Unit (CRU). (2019). “TS4.01”. Consultado el 27 de agosto del 2019 en: http://data.ceda.ac.uk/badc/cru/data/cru_ts/cru_ts_4.01/data/

DÁvila, Javier; Chowell, Gerardo; Borja-Aburto, Victor H.; Viboud, Cécile; Grajales MuÑIz, Concepción, y MilLER, Mark. (2014). "Substantial Morbidity and Mortality Associated with Pandemic A/H1N1 Influenza in Mexico, Winter 2013-2014: Gradual Age Shift and Severity". PLoS Currents Outbreaks. doi. org/10.1371\%2Fcurrents.outbreaks.a855a92f19db1d90ca955f5e908d6631 
Davis, Brian M.; Aiello, Allison E.; Dawid, Suzanne; Rohani, Pejman; Shrestha, Sourya; y Foxman, Betsy. (2012). "Influenza and Community-acquired Pneumonia Interactions: The Impact of Order and Time of Infection on Population Patterns". American Journal of Epidemiology, 175(5), 363-367. doi.org/10.1093/aje/kwr402 Fernandes-Matano, Larissa; Monroy-Muñoz, Irma Eloisa; Ángeles-MarTínez, Javier; Sarquiz-Martinez, Brenda; Palomec-Nava, Iliana Donají; Pardavé-Alejandre, Héctor Daniel; Coy-Arechavaleta, Santos Andrea; Santa-Cruz Tinoco, Clara Esperanza; GonzÁlez-IBARRA, Joaquín; GonzÁlez-Bonilla, Cesar Raúl; y MuÑozMedinA, José Esteban. (2017). "Prevalence of Non-influenza Respiratory Viruses in Acute Respiratory Infection Cases in Mexico". PLoS ONE, 12(5). doi. org/10.1371\%2Fjournal.pone.0176298

Fernández-Cantón, Sonia B.; y Perdigón Villaseñor, Gerardo. (2009). "Evolución de la mortalidad por neumonías en México 1990-2007”. Boletín Médico del Hospital Infantil de México, 67(1), 81-83.

GarcíA, Enriqueta. (2004). Modificaciones al sistema climático de Köppen. México: Instituto de Geografía, UNAM.

Global Burden Of Desease (GBD). (2015). "Estimates of the Global, Regional, and National Morbidity, Mortality, and Aetiologies of Lower Respiratory Tract Infections in 195 Countries: A Systematic Analysis for the Global Burden of Disease Study 2015". The Lancet Infectious Diseases, 17(11), 1133-1161. doi.org/10.1016/ S1473-3099(17)30396-1

Hajuar, Sami Al; y McIntosh, Kenneth. (2010). "The First Influenza Pandemic of the 21st Century." Annals of Saudi Medicine, 30(1), 1-10.

Harris, I.; Jones, P. D., Osborn, T. J.; y Lister, D. H. (2014). "Updated High- resolution Grids of Monthly Climatic Observations - The CRU TS3.10 Dataset". International Journal of Climatoly, 34(3), 623-642. doi.org/10.1002/joc.3711

The Institute of Health Metrics and Evaluation. (2020). "Mexico" (en línea). IHME. Recuperado el 3 de mayo de http://www.healthdata.org/mexico

Instituto Nacional de Estadística y Geografía (INEGI). (2010). “Censos”. Consultado el 19 de octubre de 2018 en https://www.inegi.org.mx/programas/ccpv/2010/ default.html.

Johnson, Niall P. A. S.; y Mueller, Juergen. (2002). "Updating the Accounts: Global Mortality of the 1918-1920 'Spanish' Influenza Pandemic". Bulletin of the History of Medicine, 76(1), 105-115. doi.org/10.1353/bhm.2002.0022

Kuri-Morales, Pablo; Galván, Fernando; Cravioto, Patricia; ZÁrraga-Rosas, Luis Alberto; y TAPIA-CONYER, Roberto. (2006). "Mortalidad en México por influenza y neumonía (1990- 2005)". Salud Pública de México, 48(5), 379-384.

Longini, Ira M. Jr.; Halloran, M. Elizabeth; Nizam, Azhar; y Yang, Yang. (2004).

"Containing Pandemic Influenza with Antiviral Agents". American Journal of Epidemiology, 159(7), 623-633. doi.org/10.1093/aje/kwh092

Mcallister, David A.; Liu, Li; Shi, Ting; Chu, Yue; Reed, Craig; Burroows, John; Adeloye, Davies; Rudan, Igor; Black, Robert E.; CAMPBell, Harry; y Nair, Harish. (2019). "Global, Regional, and National Estimates of Pneumonia Morbidity and 
Mortality in Children Younger Than 5 Years between 2000 and 2015: A Systematic Analysis." The Lancet Global Health, 7(1), e47-e57. doi.org/10.1016/S2214109X(18)30408-X

McCulLERS, Jonathan A. (2006). "Insights into the Interaction between Influenza Virus and Pneumococcus”. Clinical Microbiology Reviews, 19(3), 571-582. doi. org/10.1128\%2FCMR.00058-05

MorawsKa, L. (2006). "Droplet Fate in Indoor Environments, Or Can We Prevent the Spread of Infection?” Indoor Air, 16(5), 335-347. doi.org/10.1111/j.ç16000668.2006.00432.x

Morens, David M.; y Taubenberger, Jeffrey K. (2018a). "Influenza Cataclysm, 1918”. The New England Journal of Medicine, 379(24), 2285-2287. doi.org/10.1056/ NEJMp1814447

Morens, David M.; y Taubenberger, Jeffrey K. (2018b). "The Mother of All Pandemics Is 100 Years Old (and Going Strong)!”. American Journal of Public Health, 108(11), 1449-1454. doi.org/10.2105/AJPH.2018.304631

Morens, David M., Taubenberger, Jeffrey K.; y Fauci, Anthony S. (2008). "Predominant Role of Bacterial Pneumonia as a Cause of Death in Pandemic Influenza: Implications for Pandemic Influenza Preparedness". The Journal of Infectious Diseases, 198(7), 962-970. doi.org/10.1086/591708

Murdoch, Katherine M.; Mitra, Biswadev; Lambert, Stephen; y Erbas, Bircan. (2014). "What Is the Seasonal Distribution of Community Acquired Pneumonia over Time? A Systematic Review". Australasian Emergency Nursing Journal, 17(1), 30-42. doi.org/10.1016/j.aenj.2013.12.002

Musher, Daniel M.; y Thorner, Anna R. (2014). "Community-acquired Pneumonia". The New England Journal of Medicine, 371(17), 1619-1628. doi.org/10.1056/ NEJMra1312885

New, Mark; Hulme, Mike; y Jones, Phil. (1999). "Representing Twentieth-century Space-time Climate Variability. Part I: Development of a 1961-90 Mean Monthly Terrestrial climatology. Journal of Climate, 12(3), 829-856. doi.org/10.1175/15200442(1999)012<0829:RTCSTC $>2.0$. CO;2

Organización Mundial De La Salud (OMS). (2013). "Las muertes infantiles en el mundo se han reducido casi a la mitad desde 1990, dice la ONU" (en línea). Organización Mundial de la Salud. Recuperado el 20 de mayo del 2019 de https://www. who.int/mediacentre/news/releases/2013/child_mortality_causes_20130913/es/

Organización Mundial De La Salud (OMS). (2018a). "Influenza (Seasonal)" (en línea). World Health Organization. Recuperado el 10 de abril de 2020 de https:// www.who.int/news-room/fact-sheets/detail/influenza

Organización Mundial De La Salud (OMS). (2018b) "Pneumonia" (en línea). Wordl Health Organization. Recuperado el 10 de abril de 2020 de https://www.who.int/ news-room/fact-sheets/detail/pneumonia

Organización Mundial De La Salud (OMS). (2019) “Coronavirus Disease (COVID-19) Pandemic" (en línea). World Health Organization. Recuperado el 1 de abril de 2020 de https://www.who.int/emergencies/diseases/novel-coronavirus-2019 
Petrova, Velislava N.; y Russell, Colin A. (2018). "The Evolution of Seasonal Influenza Viruses". Nature Reviews: Microbiology, 16(1), 47-60. doi.org/10.1038/nrmicro.2017.118

Programa De Las Naciones Unidas Para El Desarrollo (PNUD). (2019). Informe de Desarrollo Humano Municipal 2010-2015: Transformando México desde lo local. Ciudad de México: PNUD.

Reyes Canche-Pech, Jose; Conde-Ferraez, Laura; Puerto-Solis, Marylin; GonzalezLosa, Refugio; Granja-Pérez, Pilar; Villanueva-Jorge, Salha; Chan-Gasca, Maria; Gómez-Carballo, Jesus; LóPez-Ochoa, Luisa; Jiménez-Delgadillo, Bertha; Rodríguez-SÁnchez, Iram; Ramírez-Prado, Jorge; y Ayora-TalaVera, Guadalupe. (2017). "Temporal Distribution and Genetic Variants in Influenza A(H1N1)pdm09 Virus Circulating in Mexico, Seasons 2012 and 2013”. PLoS ONE, 12. doi. org/10.1371/journal.pone.0189363

Ribot, Jesse C.; Magalhães, Antonio R.; y Panagides, Stahis. (2005). Climate Variability, Climate Change and Social Vulnerability in the Semi-arid Tropics. Cambridge: Cambridge University Press. doi.org/10.1017/CBO9780511608308

Rudan, Igor; Boschi-Pinto, Cynthia; Biloglav, Zrinka; Mulholland, Kim; y Campbell, Harry. (2008). "Epidemiology and Etiology of Childhood Pneumonia". Bulletin of the World Health Organization, 86(5), 408-416B.

Ruiz-Matus, Cuitláhuac; Kuri-Morales, Pablo; y Narro-Robles, José. (2017). “Comportamiento de las temporadas de influenza en México de 2010 a 2016, análisis y prospectiva”. Gaceta Médica Mexicana, 153, 205-213.

Shaman, Jeffrey; y Kohn, Melvin. (2009). “Absolute Humidity Modulates Influenza Survival, Transmission, and Seasonality". Proceedings of the National Academy of Science of the United States of America, 106(9), 3243-3248. doi.org/10.1073/ pnas.0806852106

Shaman, Jeffrey; Pitzer, Virginia E.; Viboud, Cécile; Grenfell, Bryan T.; y Lipsitch, Marc. (2010). "Absolute Humidity and the Seasonal Onset of Influenza in the Continental United States”. PLoS Biology, 8(2), e1000316. doi.org/10.1371/journal.pbio. 1000316

Shrestha, Sourya; Foxman, Betsy; Berus, Joshua; Van Panhuis, Willem G., Steiner, Claudia; Viboud, Cécile; y Rohani, Pejman. (2015). "The Role of Influenza in the Epidemiology of Pneumonia”. Scientific Reports, 5, 15314. doi.org/10.1038/ srep 15314

Shrestha, Sourya; Foxman, Betsy; Weinberger, Daniel M.; Steiner, Claudia; Viboud, Cécile; y Rohani, Pejman. (2013). "Identifying the Interaction between Influenza and Pneumococcal Pneumonia Using Incidence Data". Science Translational Medicine, 5(191), 191ra84. doi.org/10.1126/scitranslmed.3005982

Sistema Nacional De Información En Salud (SINAIS). (2018). Consultado el 18 de octubre de 2018 en http://www.dgis.salud.gob.mx/contenidos/sinais/subsistema1. html.

Stull, Rolland. (2017). Practical Meteorology: An Algebra-based Survey of Atmospheric Science. Vancouver: University of British Columbia. 
Wong-Chew, Rosa María; García-León, Miguel L.; Noyola, Daniel E.; Perez GonzALEZ, Luis F.; Gaitán Meza, Jesús; Vilaseñor-Sierra, Alberto, Martinez-Aguilar, Gerardo; Rivera-Nuñez, Hugo Victor; Newton-SÁnchez, Oscar A.; Firo-Reyes, Verónica; Del Río-Almendarez, Carlos N.; GonzÁlez-Rodríguez, Alejandra Pamela; Ortiz-García, Enrique R.; Navarrete-Navarro, Susana; Soria-Rodríguez, Carmen; Carrasco-Castillo, Adoniram; Sánchez-Medina, Eneida; López-Martínez, Irma; Hernández-Andrade, Teresa; Alpuche-Aranda, Celia M.; y SantosPreciado, José I. (2017). "Respiratory Viruses Detected in Mexican Children Younger than 5 Years Old with Community-acquired Pneumonia: A National Multicenter Study". International Journal of Infectious Diseases, 62, 32-38. doi. org/10.1016/j.ijid.2017.06.020 